\title{
Changes in mitochondrial function during EMT induced by TGF $\beta-1$ in pancreatic cancer
}

\author{
QINGQU GUO \\ Department of Surgery, Second Affiliated Hospital, School of Medicine, \\ Zhejiang University, Hangzhou, Zhejiang 310009, P.R. China
}

Received June 6, 2015; Accepted October 13, 2016

DOI: $10.3892 / \mathrm{ol} .2017 .5613$

\begin{abstract}
Mitochondrial dysfunction is linked to cancer. Differences in the number, morphology and function of mitochondria have been observed between normal cells and cancer cells. However, changes in mitochondrial function during epithelial-mesenchymal transition (EMT) in pancreatic cancer are less known. In the present study, the cultured human pancreatic cancer cell line Panc-1 was treated with transforming growth factor (TGF) $\beta-1$. Mitochondrial functions following TGF $\beta$-1 exposure in pancreatic cancer were investigated. It was noticed that TGF $\beta-1$ treatment induces morphologic changes and a shift from epithelial to mesenchymal phenotype in pancreatic cancer. Furthermore, increased mitochondrial mass was detected in pancreatic cancer following TGF $\beta-1$ treatment. Besides, the production of reactive oxygen species in TGF $\beta$-1-treated pancreatic cancer cells significantly increased compared with the control cells. Our results indicate that the phenomenon of EMT in pancreatic cancer has an association with mitochondrial dysfunction. Mitochondrial dysfunction may be a cause of EMT in pancreatic cancer, which leads to heterogeneity in pancreatic cancer, and may be a potential therapeutic target in the future.
\end{abstract}

\section{Introduction}

Mitochondria, which are multifunctional organelles, are important in cellular proliferation and physiology, including cellular energy (adenosine triphosphate) production via oxidative phosphorylation and apoptosis via cytochrome $c$ release (1). Mitochondrial dysfunction is linked to several human diseases, including premature aging, diabetes mellitus and cancer (2). Differences in the number, morphology and function of mitochondria have been detected between normal

Correspondence to: Dr Qingqu Guo, Department of Surgery, Second Affiliated Hospital, School of Medicine, Zhejiang University, 88 Jiefang Road, Hangzhou, Zhejiang 310009, P.R. China E-mail: quguoqing1973@163.com

Key words: mitochondrial function, EMT, TGF $\beta-1$, pancreatic cancer cells and cancer cells (3). Previous studies have revealed that mitochondrial dysfunction contributes to the development and progression of cancer (4).

The epithelial-mesenchymal transition (EMT) is a process by which cells undergo a morphological switch from the epithelial polarized phenotype to the mesenchymal fibroblastoid phenotype. During EMT, the function and expression of the epithelial cell-cell adhesion molecule E-cadherin is lost, whereas the expression of the mesenchymal cell-cell adhesion molecule $\mathrm{N}$-cadherin is induced (5). Numerous studies have previously demonstrated that EMT is often activated during cancer cell migration, invasion, metastatic dissemination and chemoresistance (6). However, changes in mitochondrial function during EMT are largely unknown. In the present study, the mitochondrial function was examined during EMT induced by transforming growth factor (TGF) $\beta-1$ exposure in pancreatic cancer. Mitochondrial DNA (mtDNA), mitochondrial mass and reactive oxygen species (ROS) increased, while the mitochondrial membrane potential $(\Delta \Psi \mathrm{m})$ decreased, following TGF $\beta-1$ treatment in pancreatic cancer.

\section{Materials and methods}

Cell culture and EMT induction. The pancreatic cell line Panc-1 was purchased from the Type Culture Collection of Chinese Academy of Sciences (Shanghai, China), and was cultured in RPMI 1640 medium (Jinuo, Hangzhou, China) containing 10\% fetal bovine serum (HyClone; GE Healthcare Life Sciences, Logan, UT, USA) $1 \mu \mathrm{g} / \mathrm{ml}$ streptomycin (Jinuo), $100 \mathrm{IU} / \mathrm{ml}$ penicillin (Jinuo), $2 \mathrm{mM}$ glutamine (Jinuo) and $1 \mathrm{mM}$ sodium pyruvate (Jinuo) at $37^{\circ} \mathrm{C}$ in a $5 \% \mathrm{CO}_{2}$ atmosphere. EMT induction by TGF- $\beta 1$ (PeproTech, Inc., Rocky Hill, NJ, USA) was performed according to a previous protocol (7). Briefly, when cells grew to $\sim 80 \%$ confluence, Panc- 1 cells were trypsinized (Jinuo) and seeded into 6-well plates in duplicate (4x10 5 cells/ well). Following 24-48 h, EMT-inducing medium (serum free, containing $1 \mathrm{ng} / \mathrm{ml}$ TGF- $\beta 1$ and $50 \mathrm{ng} / \mathrm{ml}$ epidermal growth factor) was used to replace the common medium of Panc-1 cells, and the cells were incubated for additional 24-48 h. Next, the optical density was determined.

Western blot analysis. EMT-induced Panc-1 cells were washed twice using ice-cold PBS and lysed on ice using radioimmunoprecipitation assay buffer $(20 \mathrm{mM}$ Tris- $\mathrm{HCl}$, 

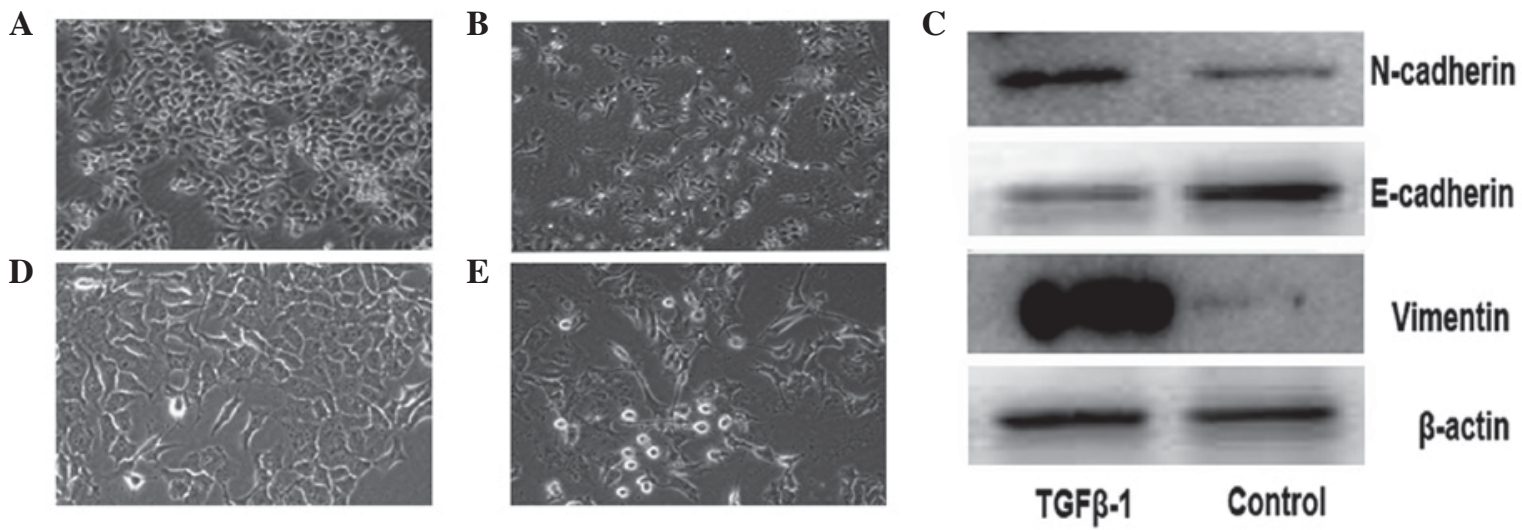

Figure 1. Morphological changes following TGF- $\beta 1$ treatment. (A) Untreated Panc-1 cells; magnification, x200. (B) Treated Panc-1 cells; magnification, x200 (C) Western blot analysis of the EMT markers vimentin, N-cadherin and E-cadherin in Panc-1 and EMT-Panc-1 cells. (D) Untreated Panc-1 cells; magnification, x400. (E) Treated Panc-1 cells; magnification, x400. TGF, transforming growth factor; EMT, epithelial-mesenchymal transition.

$150 \mathrm{mM} \mathrm{NaCl}, 1 \% \mathrm{NP}-40,0.1 \%$ SDS, $0.5 \%$ sodium deoxycholate, $2 \mathrm{mM}$ sodium fluoride, $2 \mathrm{mM} \mathrm{Na}_{3} \mathrm{VO}_{4} \cdot 2 \mathrm{H}_{2} \mathrm{O}, 1 \mathrm{mM}$ EDTA and protease inhibitor phenylmethane sulfonyl fluoride) (Beyotime Institute of Biotechnology, Haimen, China). The protein concentration of the lysates was determined using a BCA Protein Assay kit (P0009; Beyotime Institute of Biotechnology), and then marker proteins of EMT were detected using 10\% SDS-PAGE and western blotting. Cell lysates were heated at $100^{\circ} \mathrm{C}$ for $10 \mathrm{~min}$ and electrophoresed though $10 \%$ SDS-PAGE. Then, proteins were transferred to a polyvinylidene difluoride membrane (EMD Millipore, Billerica, MA, USA), which were next incubated with 5\% bovine serum albumin (BSA) (ST023; Beyotime Institute of Biotechnology) for $1 \mathrm{~h}$ at room temperature. Subsequently, membranes were incubated with the corresponding antibodies in a 5\% BSA solution at $4{ }^{\circ} \mathrm{C}$ overnight. Antibodies against $\mathrm{N}$-cadherin (14215; 1:1,000 dilution), E-cadherin (5296; 1:1,000 dilution) and vimentin (3390; 1:1,000 dilution) (8) were purchased from Cell Signaling Technology, Inc. (Danvers, MA, USA). Upon washing three times with PBS containing Tween $20[0.1 \%(\mathrm{v} / \mathrm{v})$ Tween 20, $137 \mathrm{mM} \mathrm{NaCl}, 2.7 \mathrm{mM} \mathrm{KCl}, 10 \mathrm{mM} \mathrm{Na}_{2} \mathrm{HPO}_{4}$ and $1.8 \mathrm{mM}$ $\mathrm{KH}_{2} \mathrm{PO}_{4}$ ), the membranes were incubated with horseradish peroxidase-conjugated rabbit anti-mouse immunoglobulin $\mathrm{G}$ (58802; Cell Signaling Technology, Inc.; 1:1,000 dilution) for $2 \mathrm{~h}$ at room temperature. Finally, protein bands were detected with an enhanced chemiluminescence detection kit (P0018A; Beyotime Institute of Biotechnology).

Mitochondrial density of EMT-Panc-1 cells determined by MitoTracker Green FM staining. Panc-1 cells were seeded in 6-well plates and cultured in EMT-inducing medium. After 24-48 h, Panc-1 cells in plates were stained with MitoTracker Green FM kit (Beyotime Institute of Biotechnology) according to the manufacturer's protocol to determine mitochondria density (9). Briefly, cells were firstly washed using PBS twice and then incubated at $37^{\circ} \mathrm{C}$ with $50 \mathrm{nM}$ MitoTracker Green FM probe for $30 \mathrm{~min}$. Next, the staining buffer was removed and replaced with fresh complete medium. Fluorescence was detected with a fluorescent microscope (Olympus Corporation, Tokyo, Japan), and the cells were detached for analysis using flow cytometry at $490 \mathrm{~nm}$.
Genome DNA extraction and reverse transcription-quantitative polymerase chain reaction ( $R T-q P C R)$ analysis of $m t D N A$. The mtDNA copy number of EMT-Panc-1 cells was determined by a standard protocol (10). Total genomic DNA was isolated with the Gentra Puregene Cell kit (Qiagen GmbH, Hilden, Germany) according to manufacturer's protocol. The mtDNA content was determined in cells utilizing RT-qPCR via SYBR Green assay (RR820A; Takara Biotechnology Co., Ltd., Dalian, China). The method for mtDNA copy number detection based on qPCR used a 107-bp sized amplicon of mtDNA transfer RNA (tRNA) Leu (UUR) $^{\text {(U) }}$ (forward primer, 5'-CACCCAAGA ACAGGGTTTGT-3' and reverse primer, 5'-TGGCCATGGGTATGTTGTTA-3') to determine the mtDNA copy number, and an 86-bp sized amplicon of $\beta 2$-microglobulin (forward primer, 5'-TGCTGTCTCCATGTT TGATGTATCT-3' and reverse primer, 5'-TCTCTGCTCCCC ACCTCTAAGT-3') to determine nuclear DNA (nDNA) as an internal control of the experiment (10). The PCR process consisted of 1 cycle at $95^{\circ} \mathrm{C}$ for $10 \mathrm{~min}$ followed by 40 cycles $\left(95^{\circ} \mathrm{C}\right.$ for $15 \mathrm{sec}$ and $62^{\circ} \mathrm{C}$ for $30 \mathrm{sec}$ ) and melting curve $\left(50-95^{\circ} \mathrm{C}\right.$ with a $0.5^{\circ} \mathrm{C}$ interval). qPCR was conducted in a StepOnePlus Real-Time PCR System (Applied Biosystems; Thermo Fisher Scientific, Inc., Waltham, MA, USA). PCR assays were performed in triplicate for each DNA sample. The expression of mtDNA copy number relative to that of nDNA was determined using the formula $2 \times 2^{\Delta \mathrm{Cq}}$, where $\Delta \mathrm{Cq}$ is the difference of the $\mathrm{Cq}$ values between the $\beta 2$-microglobulin gene and the tRNA ${ }^{\mathrm{Leu}(\mathrm{UUR})}$ gene.

Detection of ROS by flow cytometry and fluorescence spectroscopy. Panc-1 cells were pretreated with EMT-inducing buffer for $24-48 \mathrm{~h}$ and stained with the ROS detection probe $2^{\prime}, 7^{\prime}$-dichlorofluorescin diacetate at a final concentration of $10 \mu \mathrm{M}$ for $20-30 \mathrm{~min}$ at $37^{\circ} \mathrm{C}$. The level of ROS was detected using fluorescence spectroscopy. Subsequently, the cells were harvested and washed twice with PBS, resuspended in PBS, and analyzed by flow cytometry.

$\Delta \Psi$ m determination. $\Delta \Psi \mathrm{m}$ determination of EMT-Panc-1 cells was conducted using the lipophilic cationic fluorescent dye 5,5',6,6'-tetrachloro-1,1',3,3'-tetraethylbenzimidazolcarbocyanine iodide (JC-1) (Beyotime Institute of Biotechnology). The cells were plated and treated according to the manufacturer's protocol, and $1 \mu \mathrm{M} \mathrm{JC}-1$ was added 30 min prior to harvesting 
A

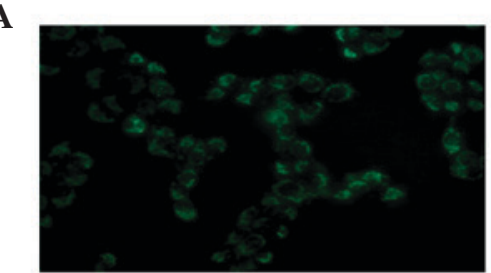

D

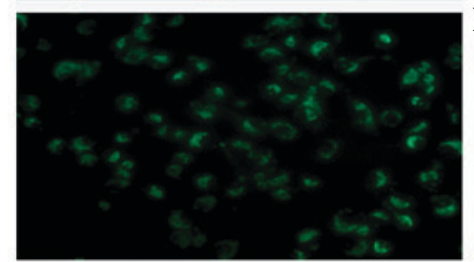

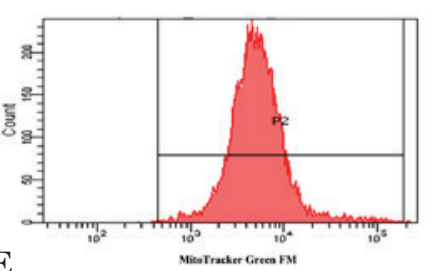

E

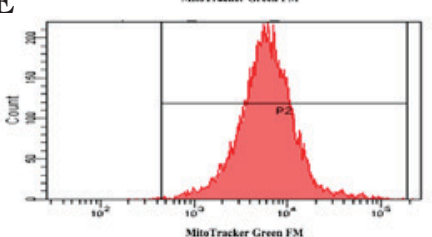

C

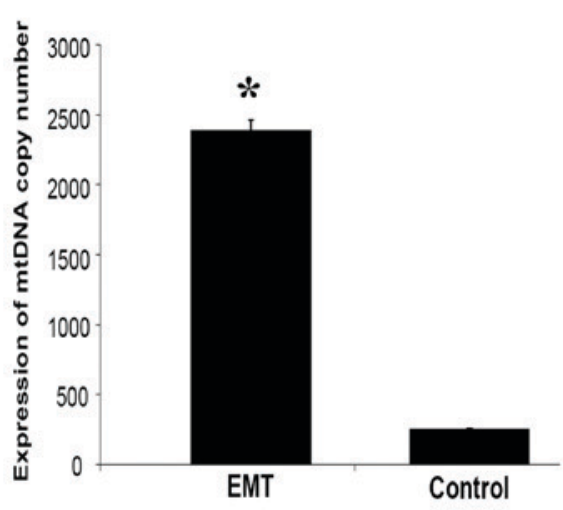

Figure 2. Increase in mitochondrial mass and mtDNA following TGF- $\beta 1$ treatment. Mitochondria were visualized by staining with MitoTracker Green FM in (A) untreated and (D) treated Panc-1 cells. Magnification, x200. Analysis of mitochondria stained with MitoTracker Green FM by fluorescence-activated cell sorting in (B) untreated and (E) treated Panc-1 cells. Images were captured with a confocal microscope. The data shown are representative of three independent experiments. (C) The intracellular mtDNA content was analyzed by reverse transcription-quantitative polymerase chain reaction with a primer for mtDNA and a primer for nuclear DNA, which served as a control. * $\mathrm{P}=0.0005$. mtDNA, mitochondrial DNA; TGF, transforming growth factor; EMT, epithelial-mesenchymal transition.

A

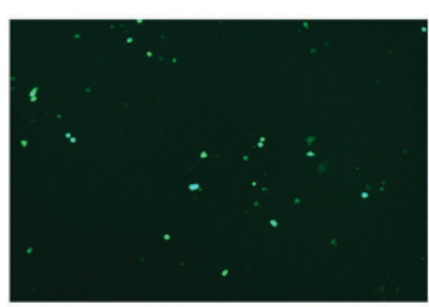

C

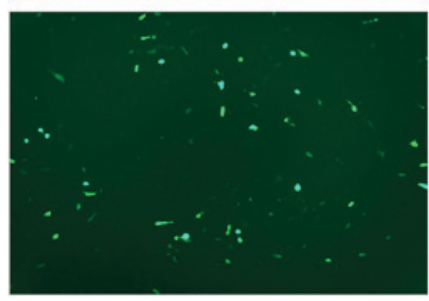

B
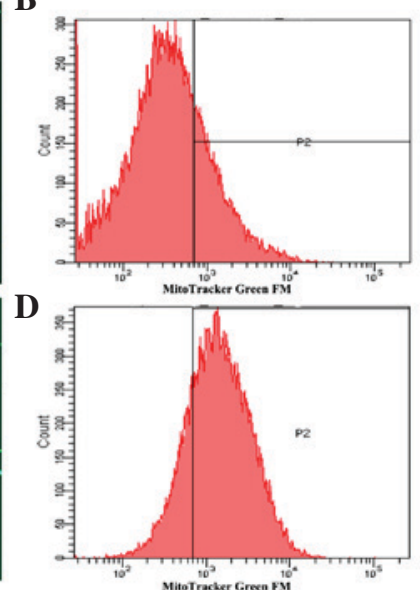

Figure 3. Increased ROS generation following transforming growth factor- $\beta 1$ treatment. Visualization of ROS by staining with DCFH-DA in (A) untreated and (C) treated Panc-1 cells. Magnification, x200. Analysis of ROS stained with DCFH-DA by fluorescence-activated cell sorting in (B) untreated and (D) treated Panc-1 cells. Images were captured with a confocal microscope. The data shown are representative of three independent experiments. ROS, reactive oxygen species; DCFH-DA, 2',7'-dichlorofluorescin diacetate.

the cells. JC-1-stained cells were firstly counted using fluorescence spectroscopy (Leica Microsystems GmbH, Wetzlar, Germany), and then the cells were collected by trypsinization and washed with PBS. The red (aggregated JC-1; R2 region) and green (monomeric JC-1; R1 region) fluorescence signals were analyzed by flow cytometry.

Statistical analysis. Data were analyzed with SPSS 19.0 software (IBM SPSS, Armonk, NY, USA) and expressed as means \pm standard deviation. The statistical significance of differences was evaluated using an unpaired, non-parametric Student's $t$ test. $\mathrm{P}<0.05$ was considered to indicate a statistically significant difference.

\section{Results}

TGF $\beta-1$ treatment induces morphological changes and a shift from epithelial to mesenchymal phenotype in pancreatic cancer. For EMT induction in cancer cells, TGF $\beta-1$, which is a major factor during EMT (11), was used. As demonstrated by Ikenaga et al (11), pancreatic cancer cells treated with TGF $\beta-1$ exhibited a spindle-shaped fibroblastic morphology and cell scattering compared with untreated cancer cells (Fig. 1). Lower E-cadherin expression, and higher $\mathrm{N}$-cadherin and vimentin expression, were detected in Panc-1 cells following treatment with TGF $\beta-1$ by western blotting (Fig. 1C). These results indicate that the pancreatic cancer Panc-1 cells acquired a mesenchymal phenotype, suggesting that EMT was induced by TGF $\beta-1$ in these cells.

Increased mitochondrial mass following TGF $\beta$-1 treatment in pancreatic cancer. To examine the mitochondrial mass upon TGF $\beta$-1 treatment, pancreatic cancer cells were stained with MitoTracker Green FM dye. As shown in Fig. 2, there were significant differences in mitochondrial mass between treated and control (untreated) cells $(\mathrm{P}=0.0004)$. Cells that underwent 

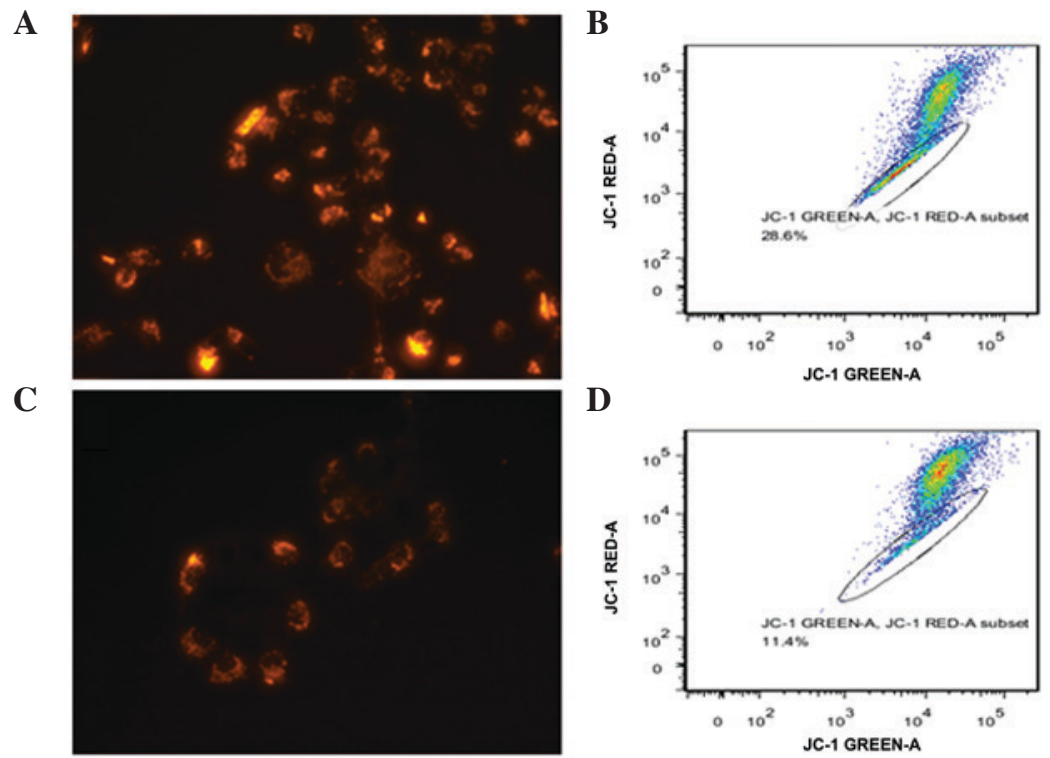

Figure 4. Decreased $\Delta \Psi \mathrm{m}$ following TGF- $\beta 1$ treatment. $\Delta \Psi \mathrm{m}$ was visualized by staining with JC-1 in (A) untreated and (C) treated Panc-1 cells. Magnification, $\mathrm{x} 200$. Fluorescence-activated cell sorting analysis of $\Delta \Psi \mathrm{m}$ upon staining with JC-1 in (B) untreated and (D) treated Panc-1 cells. Images were captured with a confocal microscope. The data shown are representative of three independent experiments. JC-1, 5,5',6,6'-tetrachloro-1,1',3,3'-tetraethylbenzimidazolcarbocyanine iodide; $\Delta \Psi \mathrm{m}$, mitochondrial membrane potential.

EMT had more mitochondria than control cells. To determine the mitochondrial mass more precisely, the fluorescence intensity of the cells was quantified immediately by flow cytometric scanning. The results of flow cytometry revealed that the mitochondrial mass of the treated group was higher than that of the control cells (Fig. 2B and E). In addition, the mtDNA content was also significantly increased in treated cells relative to that in control cells ( $\mathrm{P}=0.0005)$ (Fig. 2C).

Effect of TGF $\beta$-1 treatment on the production of ROS in pancreatic cancer cells. Mitochondria are considered the main source of ROS, and ROS production is generally associated with impairments of the respiratory chain and mitochondrial function $(12,13)$. Therefore, in order to ascertain whether alterations in the generation of ROS also occur in association with EMT, the intracellular ROS levels were measured in pancreatic cancer cells with or without TGF $\beta-1$ treatment. The results are shown in Fig. 3. The production of ROS in TGF $\beta$-1-treated tumor cells was significantly increased compared with that in control cells $(\mathrm{P}=0.004)$.

Decreased $\triangle \Psi m$ upon TGF $\beta-1$ treatment in pancreatic cancer. The present study further investigated whether TGF $\beta$ - 1 treatment affected the $\Delta \Psi \mathrm{m}$, since this is important for mitochondrial functions (14). A fluorescent probe, JC-1, was used to stain polarized mitochondria. As represented in Fig. 4A and $\mathrm{C}$, incubation with TGF $\beta-1$ decreased the number of pancreatic cancer cells displaying a high $\Delta \Psi \mathrm{m}$. Flow cytometry revealed the same results than fluorescence microscopy (Fig. 4B and D).

\section{Discussion}

The EMT is a basic physiological process in which epithelial cells lose their polarity and undergo a transition to a mesenchymal phenotype (6). Hallmarks of EMT include loss of cell-cell adhesion, re-organization of cytoskeletal actin and acquisition of migratory characteristics (15).

Emerging evidence suggests that EMT is essential in promoting tumor invasion, metastasis, recurrence and drug resistance in various types of cancer, including pancreatic cancer $(16,17)$. TGF $\beta-1$ promotes EMT by transcriptional and post-transcriptional regulation of a group of transcription factors that suppress epithelial features and enhance mesenchymal features $(18,19)$. In agreement with previous reports $(20,21)$, the present study demonstrated that TGF $\beta-1$ induces EMT in pancreatic cancer cells by acquisition of mesenchymal morphology, increased expression of the mesenchymal markers vimentin and $\mathrm{N}$-cadherin, and decreased expression of the epithelial marker E-cadherin.

Mitochondria are the primary energy producers of the cell, and regulate intracellular energy metabolism, cell death and free radical (ROS) production (22). In this context, the aim of the present study is to demonstrate the change in mitochondrial function during EMT induced by TGF $\beta-1$ in pancreatic cancer. First, mitochondrial mass and mtDNA were investigated. Human mitochondria contain a small quantity of their own DNA (mtDNA), which is essential for normal mitochondrial function (23). Changes in mtDNA content have been described in a wide variety of cancers, with both increases and decreases being reported in either tumor tissue, circulating cells or metastatic cancer cells $(24,25)$. However, in the present study, the mitochondrial mass and mtDNA content were significantly increased in TGF $\beta$-1-treated pancreatic cancer cells relative to those detected in the control cells. Furthermore, a recent study revealed that high mtDNA content is associated with tumor invasion and EMT characteristics in esophageal squamous cell carcinoma (ESCC) cells, and suggested that a relatively high mtDNA copy number may confer an advantage for tumor invasion in ESCC (26). Other studies have associated mitochondrial dysfunction with mtDNA copy number, and 
have proposed that the mtDNA content may be a potential biomarker of mitochondrial dysfunction $(23,27)$. Therefore, the increase in mitochondrial mass and mtDNA in pancreatic cancer cells with EMT phenotype observed in the present study suggests that mitochondrial dysfunction happened during the process of EMT, and may promote pancreatic cancer cell migration.

Mitochondrial dysfunction has been regarded as a hallmark of malignancy in human gastric cancer (28). Several studies have implied that mitochondrial dysfunction is important in cancer metastasis, in which induction of ROS was a key element. Thus, increased generation of ROS has an association with mitochondrial damage and dysfunction (27-29). Additionally, accumulating evidence suggests that cancer cells exhibit increased intrinsic ROS stress partly due to mitochondrial malfunction (30). In turn, excessive production of ROS in cancer cells may contribute to mitochondrial dysfunction and further lead to the stimulation of cellular proliferation, cell migration and invasion, thus contributing to carcinogenesis (31). Therefore, the current study next examined whether EMT induced by TGF $\beta-1$ resulted in excessive production of ROS in pancreatic cancer cells (32). As expected, an increase in ROS was observed in TGF $\beta$-1-treated cancer cells. This is consistent with the results of Zhou et al (33), who noticed that hypoxia-induced EMT requires the generation of mitochondrial ROS, which participate in hypoxia-induced TGF- $\beta 1$ production and results in EMT. Furthermore, a previous study reported that EMT-promoted mitochondrial dysfunction was accompanied by increased ROS generation and decreased $\Delta \Psi \mathrm{m}$ (27). Thus, determination of $\Delta \Psi \mathrm{m}$ following TGF- $\beta 1$ treatment was conducted in the present study. As previously reported, the $\Delta \Psi \mathrm{m}$ was markedly increased in the present study, suggesting that mitochondrial dysfunction occurred during the process of EMT (27).

In conclusion, the present study investigated the change in mitochondrial function that occurs during EMT induced by TGF $\beta-1$ exposure in pancreatic cancer. Our results indicate that the phenomenon of EMT is associated with mitochondrial dysfunction. Mitochondrial dysfunction may be a cause of EMT in pancreatic cancer, which leads to heterogeneity in pancreatic cancer, and may be a potential therapeutic target in the future.

\section{Acknowledgements}

The present study was supported by grants from the National Natural Science Foundation of China (Beijing, China; grant no. 81071960) and the New Teacher Foundation of Ministry of Education (Beijing, China; grant no. 20100101120129).

\section{References}

1. Kim AJ, Jee HJ, Song N, Kim M, Jeong SY and Yun J: p21 $\left(\mathrm{WAF}^{1} / \mathrm{C}^{1} \mathrm{P}^{1}\right)$ deficiency induces mitochondrial dysfunction in HCT116 colon cancer cells. Biochem Biophys Res Commun 430: 653-658, 2012

2. Kang D and Hamasaki N: Alterations of mitochondrial DNA in common diseases and disease states: Aging, neurodegeneration, heart failure, diabetes, and cancer. Curr Med Chem 12: 429-441, 2005.

3. Jose C and Rossignol R: Rationale for mitochondria-targeting strategies in cancer bioenergetic therapies. Int J Biochem Cell Biol 45: 123-129, 2013.
4. Gottfried E, Kreutz M and Mackensen A: Tumor metabolism as modulator of immune response and tumor progression. Semin Cancer Biol 22: 335-341, 2012.

5. Yilmaz M and Christofori G: EMT, the cytoskeleton, and cancer cell invasion. Cancer Metastasis Rev 28: 15-33, 2009.

6. Pirozzi G, Tirino V, Camerlingo R, Franco R, La Rocca A, Liguori E, Martucci N, Paino F, Normanno N and Rocco G: Epithelial to mesenchymal transition by TGF $\beta-1$ induction increases stemness characteristics in primary non small cell lung cancer cell line. PLoS One 6: e21548, 2011.

7. Moreno-Bueno G, Peinado H, Molina P, Olmeda D, Cubillo E, Santos V, Palacios J, Portillo F and Cano A: The morphological and molecular features of the epithelial-to-mesenchymal transition. Nat Protoc 4: 1591-1613, 2009.

8. Mani SA, Guo W, Liao MJ, Eaton EN, Ayyanan A, Zhou AY, Brooks M, Reinhard F, Zhang CC, Shipitsin M, et al: The epithelial-mesenchymal transition generates cells with properties of stem cells. Cell 133: 704-715, 2008

9. Fetisova EK, Avetisyan AV, Izyumov DS, Korotetskaya MV, Chernyak BV and Skulachev VP: Mitochondria-targeted antioxidant SkQR1 selectively protects MDR (Pgp 170)-negative cells against oxidative stress. FEBS Lett 584: 562-566, 2010.

10. Venegas V, Wang J, Dimmock D and Wong LJ: Real-time quantitative PCR analysis of mitochondrial DNA content. Curr Protoc Hum Genet Chapter 19: Unit 19.7, 2011.

11. Ikenaga N, Ohuchida K, Mizumoto K, Akagawa S, Fujiwara K, Eguchi D, Kozono S, Ohtsuka T, Takahata S and Tanaka M: Pancreatic cancer cells enhance the ability of collagen internalization during epithelial-mesenchymal transition. PLoS One 7: e40434, 2012.

12. Rigoulet M, Yoboue ED and Devin A: Mitochondrial ROS generation and its regulation: Mechanisms involved in $\mathrm{H}(2) \mathrm{O}(2)$ signaling. Antioxid Redox Signal 14: 459-468, 2011.

13. Figueira TR, Barros MH, Camargo AA, Castilho RF, Ferreira JC, Kowaltowski AJ, Sluse FE, Souza-Pinto NC and Vercesi AE: Mitochondria as a source of reactive oxygen and nitrogen species: From molecular mechanisms to human health. Antioxid Redox Signal 18: 2029-2074, 2013.

14. Brand MD and Nicholls DG: Assessing mitochondrial dysfunction in cells. Biochem J 435: 297-312,2011.

15. Chaffer CL and Weinberg RA: A perspective on cancer cell metastasis. Science 331: 1559-1564, 2011.

16. BaoB, WangZ, AliS, Kong D,Li Y,Ahmad A,Banerjee S, Azmi AS, Miele L and Sarkar FH: Notch-1 induces epithelial-mesenchymal transition consistent with cancer stem cell phenotype in pancreatic cancer cells. Cancer Lett 307: 26-36, 2011.

17. Wang Z, Li Y, Ahmad A, Azmi AS, Kong D, Banerjee S and Sarkar FH: Targeting miRNAs involved in cancer stem cell and EMT regulation: An emerging concept in overcoming drug resistance. Drug Resist Updat 13: 109-118, 2010.

18. Heldin CH, Vanlandewijck M and Moustakas A: Regulation of EMT by TGF $\beta$ in cancer. FEBS Lett 586: 1959-1970, 2012.

19. Horiguchi K, Sakamoto K, Koinuma D, Semba K, Inoue A, Inoue S, Fujii H, Yamaguchi A, Miyazawa K, Miyazono K and Saitoh M: TGF- $\beta$ drives epithelial-mesenchymal transition

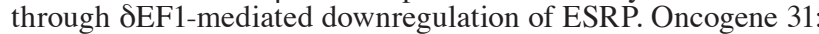
3190-3201, 2012.

20. Boreddy SR and Srivastava SK: Deguelin suppresses pancreatic tumor growth and metastasis by inhibiting epithelial-to-mesenchymal transition in an orthotopic model. Oncogene 32: 3980-3991, 2013.

21. Lou C, Zhang F, Yang M, Zhao J, Zeng W, Fang X, Zhang Y, Zhang $C$ and Liang $W$ : Naringenin decreases invasiveness and metastasis by inhibiting TGF- $\beta$-induced epithelial to mesenchymal transition in pancreatic cancer cells. PLoS One 7: e50956, 2012.

22. Chen EI: Mitochondrial dysfunction and cancer metastasis. J Bioenerg Biomembr 44: 619-622, 2012.

23. Malik AN and Czajka A: Is mitochondrial DNA content a potential biomarker of mitochondrial dysfunction? Mitochondrion 13: 481-492, 2013.

24. Yu M: Generation, function and diagnostic value of mitochondrial DNA copy number alterations in human cancers. Life Sci 89: 65-71, 2011.

25. Sotgia F, Whitaker-Menezes D, Martinez-Outschoorn UE, Flomenberg N, Birbe RC, Witkiewicz AK, Howell A, Philp NJ, Pestell RG and Lisanti MP: Mitochondrial metabolism in cancer metastasis: Visualizing tumor cell mitochondria and the 'reverse Warburg effect' in positive lymph node tissue. Cell Cycle 11: 1445-1454, 2012 
26. Lin CS, Lee HT, Lee SY, Shen YA, Wang LS, Chen YJ and Wei YH: High mitochondrial DNA copy number and bioenergetic function are associated with tumor invasion of esophageal squamous cell carcinoma cell lines. Int J Mol Sci 13: 11228-11246, 2012.

27. Yuan Y, Chen Y, Zhang P, Huang S, Zhu C, Ding G, Liu B, Yang $\mathrm{T}$ and Zhang A: Mitochondrial dysfunction accounts for aldosterone-induced epithelial-to-mesenchymal transition of renal proximal tubular epithelial cells. Free Radic Biol Med 53: 30-43, 2012.

28. Hung WY, Huang KH, Wu CW, Chi CW, Kao HL, Li AF, Yin PH and Lee HC: Mitochondrial dysfunction promotes cell migration via reactive oxygen species-enhanced $\beta 5$-integrin expression in human gastric cancer SC-M1 cells. Biochim Biophys Acta 1820: 1102-1110, 2012.

29. Ma J, Zhang Q, Chen S, Fang B, Yang Q, Chen C, Miele L, Sarkar FH, Xia J and Wang Z: Mitochondrial dysfunction promotes breast cancer cell migration and invasion through HIF1 $\alpha$ accumulation via increased production of reactive oxygen species. PLoS One 8: e69485, 2013.
30. Moreno-Sánchez R, Rodríguez-Enríquez S, Marín-Hernández A and Saavedra E: Energy metabolism in tumor cells. FEBS J 274: 1393-1418, 2007.

31. Ishikawa $\mathrm{K}$, Takenaga $\mathrm{K}$, Akimoto $\mathrm{M}$, Koshikawa $\mathrm{N}$, Yamaguchi A, Imanishi H, Nakada K, Honma Y and Hayashi J: ROS-generating mitochondrial DNA mutations can regulate tumor cell metastasis. Science 320: 661-664, 2008.

32. Bonnard C, Durand A, Peyrol S, Chanseaume E, Chauvin MA, Morio B, Vidal H and Rieusset J: Mitochondrial dysfunction results from oxidative stress in the skeletal muscle of diet-induced insulin-resistant mice. J Clin Invest 118: 789-800, 2008.

33. Zhou G, Dada LA, Wu M, Kelly A, Trejo H, Zhou Q, Varga J and Sznajder JI: Hypoxia-induced alveolar epithelial-mesenchymal transition requires mitochondrial ROS and hypoxia-inducible factor 1. Am J Physiol Lung Cell Mol Physiol 297: L1120-L1130, 2009. 